\title{
Gaming techniques and the product development process: commonalities \& cross-applications
}

Andrew Wodehouse

University of Strathclyde

andrew.wodehouse@strath.ac.uk

David Bradley

University of Abertay Dundee

d.bradley@abertay.ac.uk

\begin{abstract}
The use of computer-based tools is now firmly embedded within the product development process, providing a wide range of uses from visualisation to analysis. However, the specialisation required to make effective use of these tools has led to the compartmentalisation of expertise in design teams, resulting in communication problems between individual members. This paper therefore considers how computer gaming techniques and strategies could be used to enhance communication and group design activities throughout the product design process. A range of game have been examined with a view to utilisation in support of the product development process, with commonalities and cross-applications identified. In light of this, a novel structural representation of the design process has been suggested which allows team members to interact in group design tasks and project management through gaming activities. It is concluded that development of gaming interactions has the potential to significantly improve the performance of large and remote design teams.
\end{abstract}

\section{Keywords}

Computer games, design process, product development, gaming techniques, game genres

\section{Introduction}

Engineering design is a complex, problem solving process which requires a wide range of information and ideas to be communicated amongst team members if it is to be successful (Rogers and Lea, 2005). Indeed, it is often in this area of communication that errors occur, both in the form of misunderstanding and in poorly contextualised or inappropriate information (Wodehouse and Bradley, 2003). With the widespread usage of computerbased tools this problem may be exacerbated, as they require significant levels of expertise to achieve the best performance. This then requires the 'expert tool user' to act as the link between other members of the design team and the tool, which can be seen as distancing these non-expert users from a particular aspect of the design process.

Addressing this breakdown in communication is the primary motivation behind this paper.

Computer games can be helpful in thinking about how team members communicate in a virtual space. In multi-player computer games, players engage with information and communicate with others at a highly sophisticated level, dealing with large amounts of 
information and interacting in a complex way to reach a common goal. By utilising gaming techniques, a virtual design environment can provide a more engaging collaborative forum for the design team both in terms of project management and design activity. During the course of a game, players are repeatedly presented with a wide range of concepts and scenarios which they must rapidly assimilate and select from in order to progress. Computer games provide a structured framework through which players must navigate, but each time played in a different manner. Structuring the ways in which users navigate and move through the product design process by controlling the allowable inputs and outputs in a manner similar to this could allow action and reflection to be configured for optimal decision making (Manninen, 2003). Additionally, there are significant similarities between the information and knowledge transfer requirements in terms of developing expertise, exploring possible solutions and working with others towards a successful outcome.

The primary reason for considering the use of gaming techniques and strategies is therefore to enhance communication by providing interfaces between system users and computer-based tools which are more engaging and which require minimal special expertise for their use. Good computer games are highly effective in involving users, but generally have little educational or communications context (Norman, 2004). On the other hand, many design and management tasks are often perceived as being tedious. Despite the similarities, there has been relatively little study into how some of the qualities of computer games could be utilised to compliment the design task (Ip and Jacobs, 2004; Squire, 2002). Thus this paper seeks to answer two main research questions:

- How can computer gaming techniques and strategies be used to enhance communication and group design activities in product development teams?

- What framework or methods can be used to combine and utilise the most desirable features of these games?

\section{Interaction of design teams}

There have been several previous attempts to integrate different aspects of the design process using computer-based tools (Broadbent et al, 1999; Davis, 2000; Roller et al, 2002), primarily concerned with information flows. The fact that the bulk of design information is stored digitally means it has the potential to be retrieved and utilised quickly - ideal for the dynamic nature of the design process. However, these systems do not address characteristics of team interaction. The problem persists of team members from various disciplines working at designated parts of the process, developing expertise in specific computer-based tools and not necessarily considering the communication of the data generated across the team and the design process as a whole. It is how system users interact in this environment which determines its effectiveness, and is where gaming strategies have the possibility of making a significant contribution.

\subsection{The design process}

For the purpose of this paper, Pugh's (1991) design process has been used as a framework for product development as it outlines the typical design stages in an uncomplicated fashion, while being concerned with the cross-visibility of different disciplines in relation to the core design activity. In this and other typical methodologies, the design process is considered as essentially linear, iterative process where problems 
are defined and then solved (Pahl and Beitz, 1988; Ulrich and Eppinger, 1995). In reality, in many product development situations 'solution' and 'problem' are tightly coupled or linked, creating difficulties in reaching a conclusion unless taken together. This may include the definition of the problem or the creation of solutions outside the original boundaries. In an information rich environment, there is often confusion amongst team members about where in the engineering design process they are, and the next steps required to move a project towards completion. This is especially applicable to large or remote design teams, where it is necessary to manage and conduct large parts of the design activity in the virtual environment. Since current computer tools are focussed towards solving specific design problems (e.g. mind-mapping, CAD, finite element analysis) and not necessarily integrated, it is important to consider new and innovative methods for drawing together team members and engaging with all the information generated by the team.

Table 1 shows the product development process as it has been considered here, with typical tasks shown for the five development stages. Inputs, outputs, tools and information have been considered at each stage in the process in order to help deduce possible crossapplications with existing computer games. The needs of the various design stages can then be considered with respect to computer games and the possibilities they offer.

Table 1: Activities in the product development process

\begin{tabular}{|c|c|c|c|c|c|}
\hline & Market & Specification & Concept design & Detail design & Manufacture \\
\hline 号 & Market analysis & Develop PDS & $\begin{array}{l}\text { Generate, select and } \\
\text { embody concept }\end{array}$ & Detail concept & $\begin{array}{l}\text { Optimise design for } \\
\text { manufacture }\end{array}$ \\
\hline $\begin{array}{l}\text { 글 } \\
\text { 으 }\end{array}$ & $\begin{array}{l}\text { Legislation, reports, } \\
\text { competitive products, } \\
\text { statistics, market data }\end{array}$ & $\begin{array}{l}\text { Market analysis } \\
\text { results }\end{array}$ & PDS document & Layout drawing & Detailed drawing \\
\hline $\begin{array}{l}\text { d } \\
\frac{c}{0} \\
\mathbb{0} \\
\frac{0}{0} \\
\frac{0}{0} \\
\frac{0}{0} \\
\frac{0}{0}\end{array}$ & $\begin{array}{l}\text { User behaviour } \\
\text { capture tools } \\
\text {-Parametric analysis } \\
\text {-Needs analysis } \\
\text {-Matrix analysis }\end{array}$ & $\begin{array}{l}\text { Objectives tree } \\
\text { Competitive } \\
\text { benchmarking } \\
\text { Comparative analysis } \\
\text { Word processors } \\
\text { Spreadsheets }\end{array}$ & $\begin{array}{l}\text { Brainstorming } \\
\text { Sketching and } \\
\text { rendering } \\
\text { Decision tools } \\
\text {-Weighted objectives } \\
\text { tree } \\
\text {-QFD } \\
\text {-Morphological chart }\end{array}$ & $\begin{array}{l}\text { Performance } \\
\text { specification methods } \\
\text { 3D modeling } \\
\text { Finite Element } \\
\text { modeling } \\
\text { Engineering analysis } \\
\text { 2D draughting }\end{array}$ & $\begin{array}{l}\text { Simulation and } \\
\text { computer analysis } \\
\text { Laboratory } \\
\text { experiments } \\
\text { Design for } \\
\text { manufacture } \\
\text { Process planning } \\
\text { Process simulation }\end{array}$ \\
\hline 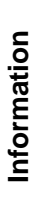 & $\begin{array}{l}\text { User observations } \\
\text { Market surveys } \\
\text { Forecasts and trends } \\
\text { Details on competing } \\
\text { products } \\
\text { Patent Database }\end{array}$ & $\begin{array}{l}\text { Performance of } \\
\text { competing products } \\
\text { User specifications }\end{array}$ & $\begin{array}{l}\text { 'Standard' functions } \\
\text { (i.e. common } \\
\text { mechanisms) } \\
\text { Comparative analysis } \\
\text { Discussion }\end{array}$ & $\begin{array}{l}\text { Standard part } \\
\text { catalogues } \\
\text { Material databases } \\
\text { Manufacturer's on-line } \\
\text { catalogues }\end{array}$ & $\begin{array}{l}\text { Available } \\
\text { manufacturing } \\
\text { processes and } \\
\text { facilities } \\
\text { Comparative costs }\end{array}$ \\
\hline$\frac{5}{3}$ & $\begin{array}{l}\text { Market analysis } \\
\text { results }\end{array}$ & PDS document & Layout drawing & Detailed drawing & Production plan \\
\hline
\end{tabular}

\subsection{Game-based interaction}

An entire generation has now grown up in a digital arena populated by instant and visual games. This environment is part of the modern mindset, and computer users demand a higher and more sophisticated level of engagement with computer games than ever before (Gee, 2003). There is also a growing industry based around game-based corporate team- 
building and training, where the key aim is to utilise the huge potential of software to make these activities more engaging. The application of this interactive element of computer gaming to the design process provides an opportunity to create a powerful cross-company tool. According to Prensky (2001) games hold several key advantages:

- Games give us enjoyment and pleasure.

- Games spark our creativity.

- Games give us doing.

- Games give us learning.

- Games give us adrenalive.

- Games give us structure.
- Games give us intense and passionate involvement.

- Games give us motivation.

- Games give us flow.

- Games give us ego gratification.

- Games give us social groups.

- Games give us emotion.

If games are to provide higher levels of engagement, the player must be able to interact convincingly with the virtual environment provided by the game platform. Newman (2002) has stated:

The On-Line relationship between primary-player and system/gameworld is not one of clear subject and object. Rather, the interface is a continuous feedback loop where the player must be seen as both implied by, and implicated in, the construction and composition of the experience.

Games work by integrating a number of structures. These include components such as the narrative element, addictive gameplay elements or intriguing puzzles. The literal forms of communication used within each of these structures will dictate how effective the game will be in involving its players. In this context, Fig. 1 shows different forms of interaction typically involved in playing a computer game (Manninen, 2001). As well as providing a loose framework to categorise the forms of interaction in multiplayer games, these individual categories draw attention to the different communication tools and techniques used. Most forms of direct human communication rely on the reading of subtle signs and clues. When playing a game and communicating with other people in this virtual environment, many of these signs are lost in the cruder format. This has consequences for different types of design activities and decisions being taken and it is therefore important to understand how gaming achieves such high levels of engagement from participants and how in the context of design teams a similar result can be achieved (Mark and Wulf, 1999). The following section therefore identifies a framework for examining a selection of computer games with respect to the communication in and management of design teams. 


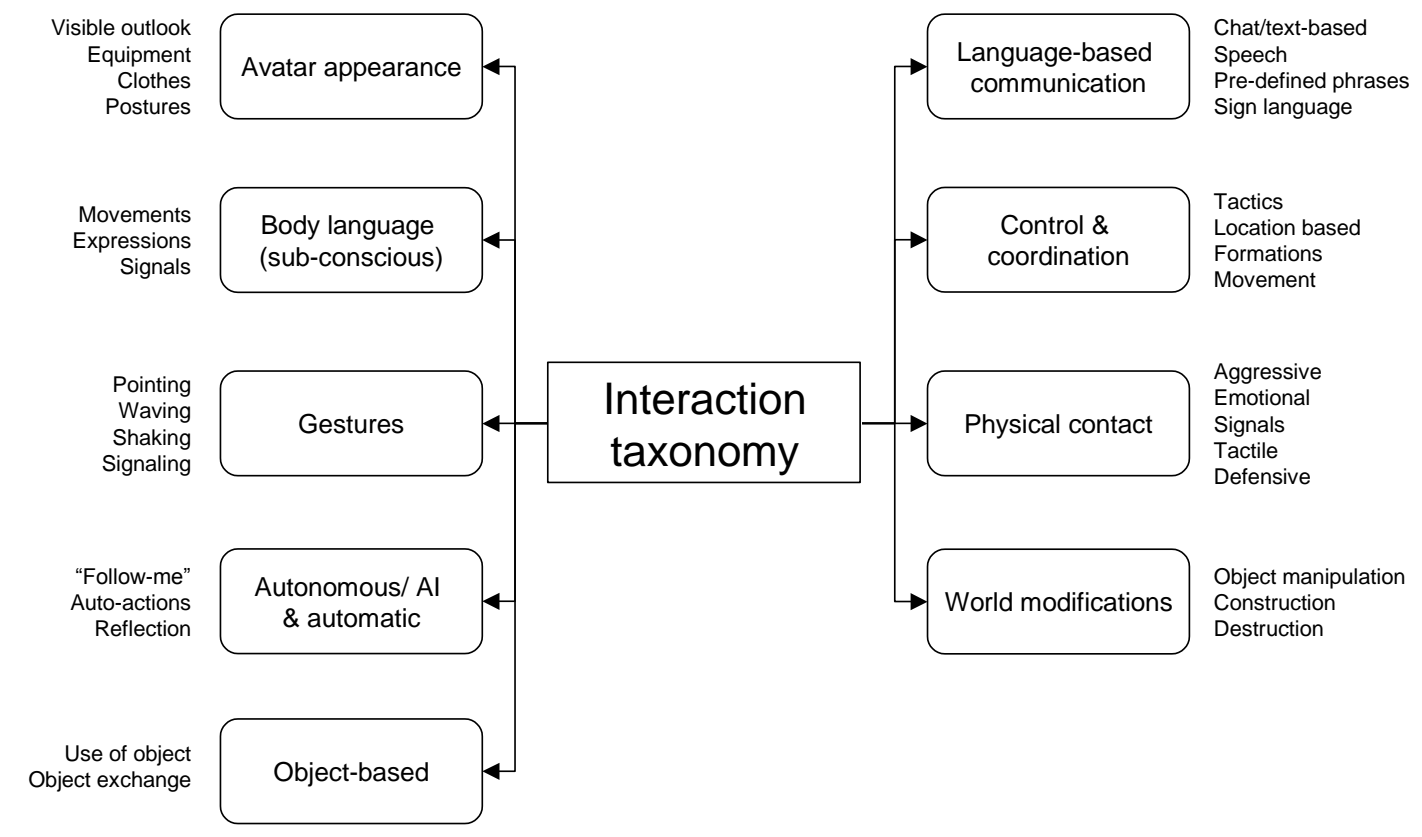

Figure 1: Taxonomy of interaction forms (Manninen, 2001)

\section{Game selection}

Several games from a range of genres were identified and tested. Table 2 lists the games which were selected for closer examination, and also provides an outline of the content. They are recognised as being games of excellence and/or popularity in their respective genres and are recognisable to generations of gamers. Thus, elements derived in whole or in part from these games should be familiar to anyone with experience of computer games.

Table 2: Games selected for evaluation

\begin{tabular}{lll}
\hline Genre & Game & Description \\
\hline $\begin{array}{l}\text { Real-time } \\
\text { strategy }\end{array}$ & $\begin{array}{l}\text { Age of Empires II } \\
\text { Command \& } \\
\text { Conquer } \\
\text { Simulation }\end{array}$ & $\begin{array}{l}\text { Conquer other civilisations, accumulate wealth by trading and diplomacy, build and defend } \\
\text { empires. } \\
\text { A war game commanding troops to attack or defend positions. }\end{array}$ \\
The Sims & $\begin{array}{l}\text { Build houses, shops and amenities to create a city and then manage utilities and resources } \\
\text { to help it develop. The city and its inhabitants will respond to every decision made. } \\
\text { Create a neighbourhood for the 'Sims' and run their daily lives. Open-ended gameplay } \\
\text { gives the freedom to set own goals and chart the Sims' destiny. }\end{array}$ \\
Action & $\begin{array}{l}\text { Interact with a richly coloured environment and a large cast of characters through } \\
\text { structured dialogue. Based around a series of puzzles, and features drama, intrigue and } \\
\text { humour. }\end{array}$ \\
& Monkey Island & $\begin{array}{l}\text { A combination of narrative driven and non-linear gameplay and a completely open } \\
\text { environment, the game features mainly driving, and shooting action, with some strategy } \\
\text { based content. }\end{array}$ \\
\hline
\end{tabular}

A key factor in the use of game-based tasks is that gameplay and content have equal importance. A game engine with the activity content 'bolted on', as with The Monkey Wrench Conspiracy (Prensky, 2001) where the user designs tools in CAD to help them complete an adventure in space, must be carefully balanced to ensure the user is not simply offered chunks of 'fun' play as a carrot to endure 'tasks' which are perceived as boring. Examples of popular games where the gameplay and setting have been tightly interwoven to provide a rich and engaging environment have therefore been sought. Each game was played and analysed for elements pertinent to game-based work and 
communication. For evaluation purposes, the games were considered in relation to a broad set of attributes, as shown in Table 3, derived from Manninen's (2001) interaction taxonomy. This provided a framework of subjective indicators with which to evaluate the games with respect to structure and player communication.

Table 3: Game topic areas

\begin{tabular}{l|ll}
\hline Attributes & Game structures & Interaction \\
\hline Risk & Decision making: type, frequency, complexity & Language-based communication \\
& Risk mitigation: volume of information, consequences, rewards & Control and coordination \\
& Strategy: Micro/macro decisions, Long/short term & Autonomous/Al \& automatic \\
Pressure & Time limit: timeframe, variation, consequences & Control and coordination \\
& Skill level: variation, dexterity, puzzles & Gestures \\
& Pressure segments: introductory sequence, in-game cut-aways & Autonomous/Al \& automatic \\
Environment & Variation, complexity, realism & World modifications \\
& Implementation: theoretical basis, rule set, structure & Object-based \\
& Gameplay: format, avatars, Al & Avatar appearance \\
Simulation & Time-line, narrative format, maintenance & Autonomous/Al \& automatic \\
& Multi-player: number, interaction & Avatar appearance \\
& Information: competition, collaboration & Language-based communication \\
Impact & Repetition, engagement, longevity & Pysical contact \\
& Knowledge: acquiring, use, relevance & Control and coordination \\
& Learning: stated/integrated, continuity, format & Language-based communication \\
\hline
\end{tabular}

\section{Discussion}

The games were evaluated by the author from a perspective of having industrial experience in product design and development, but little in computer gaming. This allowed the games to be considered with respect to how they could impact on typical design group activities and management. This was done by creating an evaluation checklist where impressions were recorded while playing the games. These impressions have been formulated and captured in the following section.

\subsection{Real-time strategy games}

Real-time strategy (RTS) games (as opposed to traditional turn-based games) are ones which progress in real time, with players making continuous decisions. Teams are required to engage in the micro- and macro-management of an often complex set of variables to achieve a fixed goal. It is a dynamic gaming environment which requires players to respond quickly to changing circumstances. Avatars were found to play an important role in the RTS environment: players from multi-player teams would be represented in the virtual environment and the actions of the avatar in this environment were the primary mode of communicating with other players. In addition to this, control and coordination played a crucial role in the game. Players do not need to be present at all times: the the use of avatars and an accessible interface allows someone to quickly surmise the current game situation if they have been absent for a period of time. This mixture of both sychronous and asynchronous game components has proven to be useful in team communication and negotiation tasks (Asakawa and Gilbert, 2003). A typical RTS game may be military, involving the control of armies, squadrons and individual troops, with the strategies and tactics used in this making up the main element of skill in the game. As well as this, they generally require a high number of mouse clicks, as world modification of the environment continues at a fast pace, ensuring that the game remains engaging for the players involved. Although these games can be played by a single player, the trend is for larger teams, with massive multi-player online games (MMORTS) where large numbers of 
remote players can be involved in the game at once becoming increasingly popular. These conditions have obvious parallels to the management of a global design team.

The Play2Win (2005) project is a collaborative research programme on how a game-based approach can help organisations motivate, train and develop employees to enhance their performance. Within this programme, BusinessLab (2005) are currently examining how publicly available computer games can be used within a commercial context to aid and facilitate the growth and development of virtual teams. The aim is to provide a safe and fun environment in which virtual teams can be fostered within an organisation, thereby overcoming geographical, technological and communication barriers. They have identified a possible means of achieving enhanced communication within virtual teams through the use of multi-player strategy games such as Age of Empires and collaboration software such as Groove, as illustrated in Fig. 2. The stakeholders are set a number of team challenges which require them to work together to achieve game objectives and to ultimately develop for themselves a strategy that will allow them to work together to achieve a common goal. The strategy that they develop must be collaborative and will test the communication skills, hopefully overcoming some of barriers that might exist when using current technology. The platforms are not used synchronously but rather are designed to be used independently. For example, the team will use Groove to develop a strategy for playing the game collaboratively through the sharing of documents, chat, weblinks and so forth. This will then be executed in The Age of Empires game. Teams can then return to the Groove platform to reflect on how the game went and refine their approach. This illustrates that by enhanced inter-player communication and information management features, RTS games can provide a medium for strongly engaging a group of people.

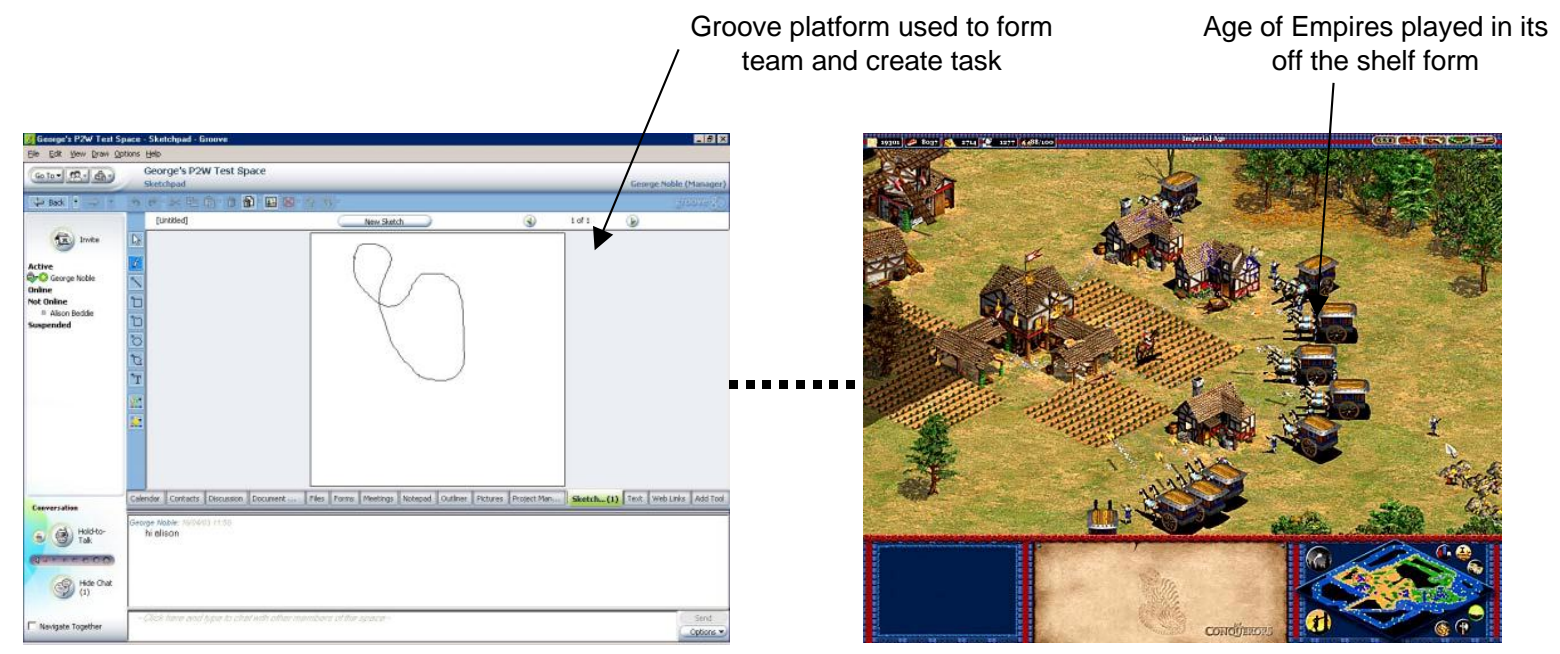

Age of Empires II: (C) 1998 Microsoft Corporation. All rights reserved. Groove: (c) 2002-2005 Groove Networks. All rights reserved.

Figure 2: BusinessLab's Age of Empires/Groove virtual team experiment

\subsection{Simulation games}

A simulation (Sim) game is a mixture of skill, chance and strategy which results in the complex representation of a system, such as a stock exchange or a civilization. There was found to be a large amount of data to be managed in these simulations, with mult-layered interfaces to help the player organise both visual and textual information. Help systems were delivered via 'advisers' to aid the player, and this was a highly effective way of 
guiding the player through the game without being prescriptive. Sim games are less multiplayer orientated than other genres, as they are primarily concerned with adjusting variables to examine the effect on a complex system. A potential problem with this is that the games are a simulation of a specific environment: if information or variables are introduced from outside (e.g. the Internet) then intelligent agents are required to seek out information in the background and present it as game content. The most obvious comparison with the design process is with the setting and adjustment of design constraints, and using the information-rich system to familiarise someone with a particular design problem.

In The Sims game, there exists a neighbourhood of characters which must be managed through their daily lives by the player. It is possible to imagine each house and its members representing a different department in a company (Fig. 3) rather than just a residential area. If the aim of each house/department is to satisfy the inhabitants, as in the Sims game, then by using a different set of metrics to achieve this, the result could be a game where information, constraints and ideas and are manipulated to produce a satisfactory design concept. For example, items in the manufacturing department could represent different materials the designer has access to. Each material has a set of constraints and if a material is selected then the design must be altered to suit these. The conversations of characters in the game bring the constraints to life: elements of gesture and body language delivered by on-screen avatars can be a powerful way to reinforce these. An online version of the Sims is in development, which will allow players to exchange characters, collect items of furniture and so on. A future environment where the intelligent agent embedded in the software could locate specific information as a background task and seamlessly integrate with the database of knowledge already within the game confines would allow a product development game to grow and expand with each project completed.

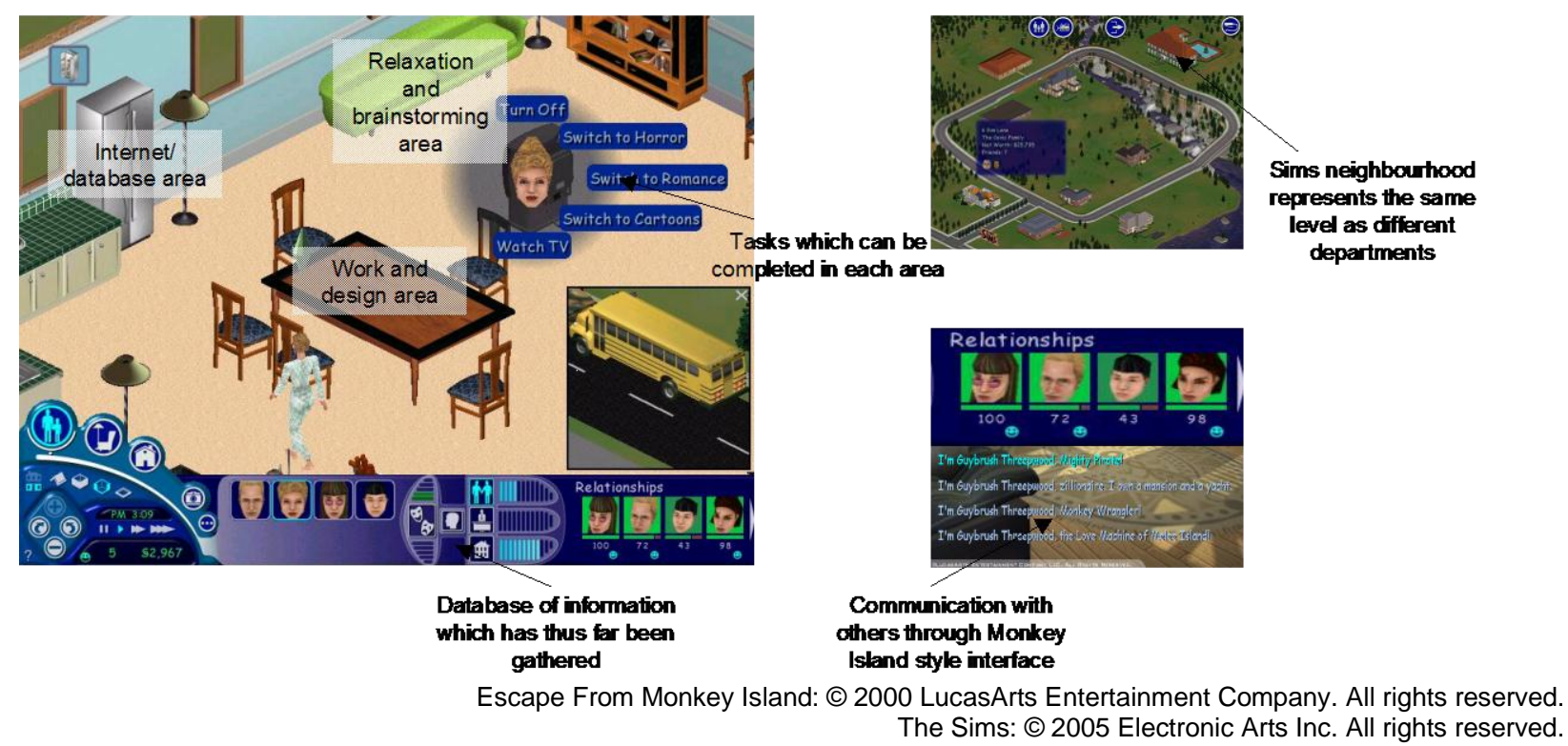

Figure 3: Possible knowledge transfer interfaces

\subsection{Role playing games}

Role playing games (RPG) are forms of interactive and collaborative storytelling games, which tend to focus on the role-playing aspect of behaviour. Stimulators in the form of Al and world modification were found to be crucial in moving the player through a fantasy 
world. Information was transmitted through both language and symbols and these tended to be spontaneous interactions rather than deep, strategy based thinking. Creativity is an increasingly valued attribute in a competitive business environment, but according to Goldenberg and Mazursky (2002), "... most investigators have encountered difficulties in devising an approach through which to organize, investigate and emulate the phenomenon of creativity". In recent years a multitude of tools and techniques such as suggestion systems (Fairbank et al, 2003) have been developed to draw out the creative tendencies of all workers, not just those in the traditionally artistic pursuits. Many creative techniques such as brainstorming tend to rely on bringing a group together and facilitating a structured idea generation process. The key to success in these types of session is a low-pressure, low-consequence environment where people feel free to contribute with whatever comes to them. From this point of view, the fantasy environment provided by RPG games is ideal. The design members can assume other personalities or environments which could stimulate new ideas and ways of looking at a problem. Techniques such as these are most applicable in the concept design stage of Pugh's product design process, as this as where new ideas are created and explored.

Escape From Monkey Island consists of navigating through a 3D world to engage in a series of structured dialogues with other characters in order to solve problems. In an environment such as this, the player can ask questions of a diverse range of characters to encourage divergent thinking. Figure 4 shows a scenario for using this environment as the basis for stimulating creative design thinking with respect to a design task- designing a mug. Some method to visually store and display the ideas and variables gathered would however be required for rapid access to the information accumulated, and for this an interface such as that used in a Sim game like Sim City would be appropriate. This consists of a multi-layered interface with detailed information on all aspects of the game easily accessible. An additional requirement is for an active area where the user can develop ideas and solutions to the problem as the new ideas are stimulated, as shown on the right of the Fig. 4. Communication with other players (trading ideas etc.) would also be possible through the information panel at the bottom.

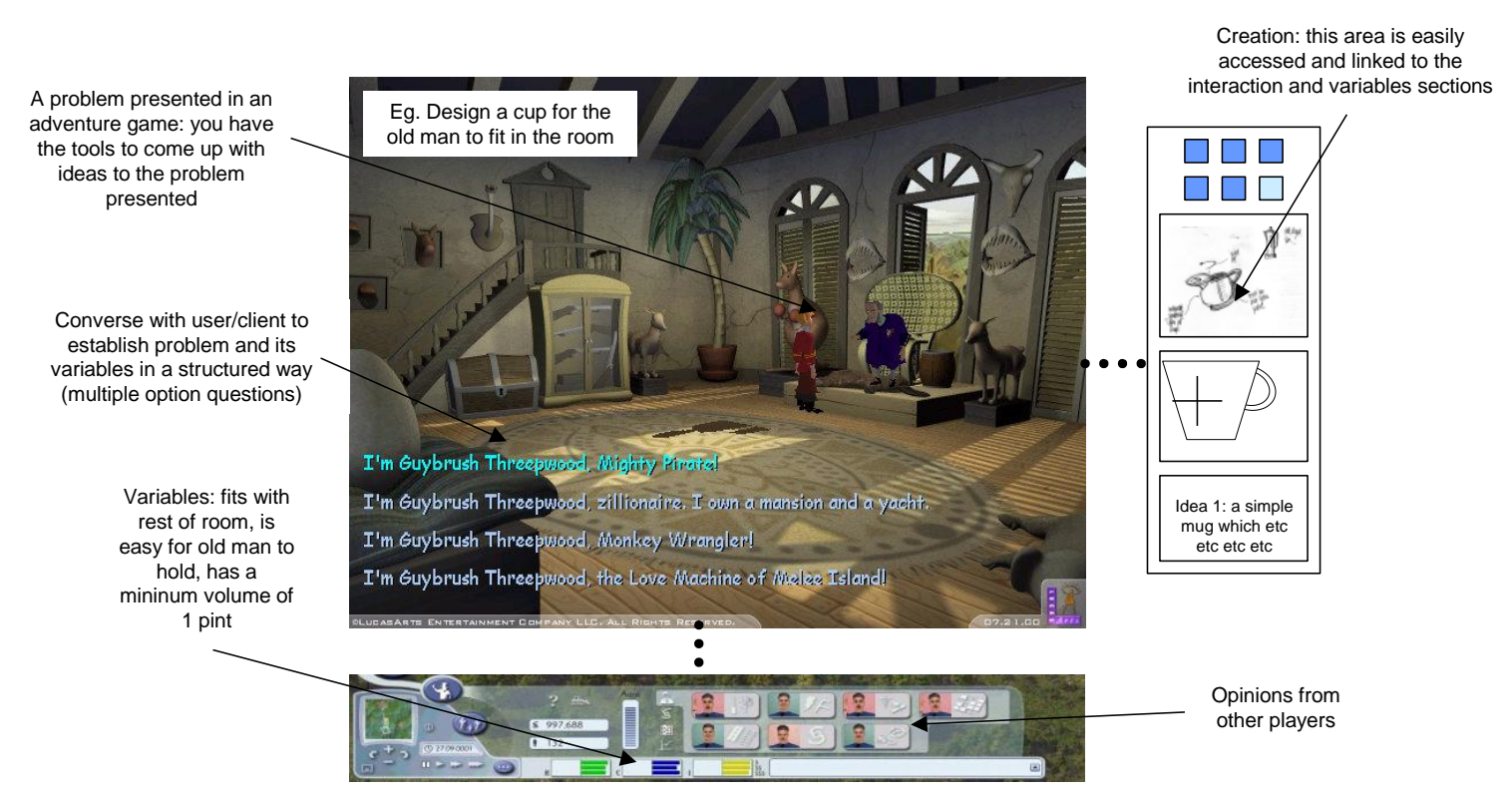

Escape From Monkey Island: (C) 2000 LucasArts Entertainment Company. All rights reserved. Sim City 4: ( 2005 Electronic Arts Inc. All rights reserved. 
Figure 4: Creativity scenario- designing a mug

\subsection{Action Games}

Action games are primarily concerned with gameplay, such as racing simulations or flight simulations, and can vary in realism while generally relying on an element of skill. They were found to be generally first-person perspective games viewed through the eyes of a fictitious character. Control and coordination in the object manipulation of a vivid world representation was the main focus of player interaction. Al was important in ensuring that the virtual world reacted in an accurate or appropriate way to the player actions, and some elements of avatar and language communication became important when multi-player games were undertaken. Players could play against each other or as part of a team. Skills are generally acquired through practice and feedback (Coyne, 2003), with increasing challenges to maintain interest. Unless training is being performed for a specific task, this type of game is probably the most difficult to integrate with learning or productive content. On the other hand, this type of game is that which can evoke the strongest emotions in players: one only has to look at the driving and shooting games which have dominated the market for years. They are seen as glamorous, exciting and fun and the challenge is to try and migrate some of these elements into team work and task completion. Interestingly, a game does not necessarily have to be realistic, but it does have to be compulsive playing to be a success. The balance of these two factors provided the basis of examination of this area which is probably most applicable to the part of the design process where some action-orientated task is being undertaken simultaneously by players to reach a consensual decision.

If, for example, a program was to be used to help teach taxi drivers to navigate around a town (as in Fig. 5), a game engine such as Grand Theft Auto could be used with an accurate city map replacing the current imaginary city. Various strategic features such as those employed in an RTS game such as Command \& Conquer could help teach the driver about the quickest route with consideration to traffic flows at different times of the day, as well as alternative routes if there are roadworks and other distractions. By allowing different drivers to use the game either synchronously or asynchronously, individual performance or co-ordinated driver tasks could be examined.
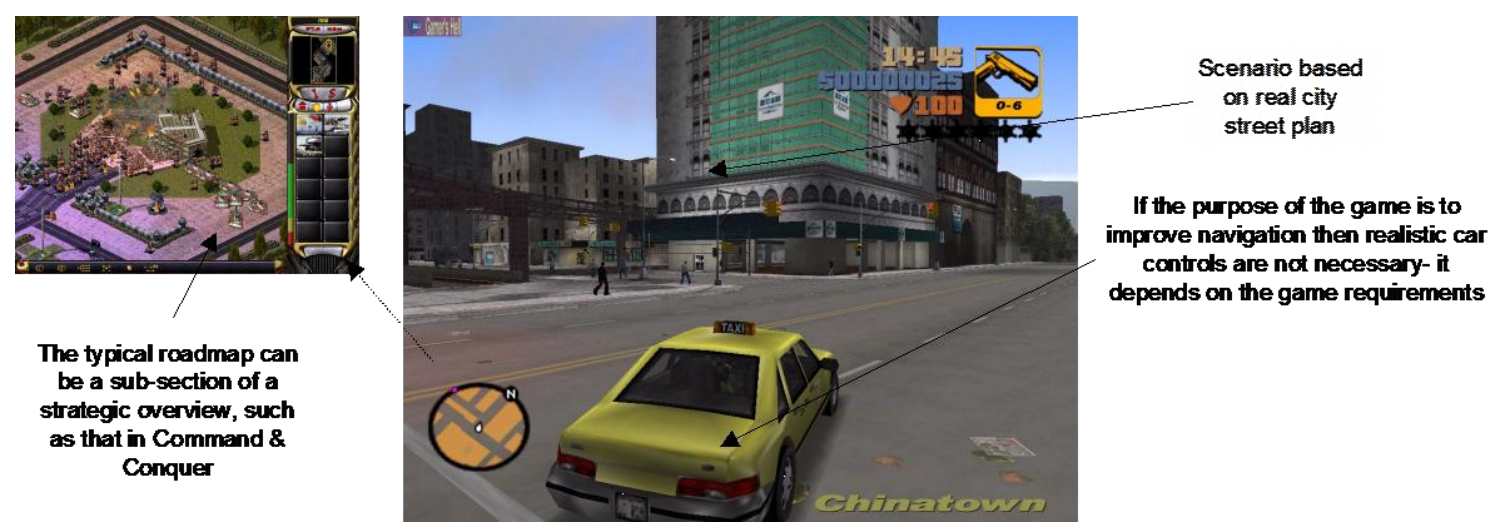

Grand Theft Auto: () 1998 Rockstar Games. All rights reserved. Command \& Conquer: (c) 1996 Electronic Arts Inc. All rights reserved.

Figure 5: Possible skill development interface 


\section{Gaming in the design process}

In this section, activities undertaken in each stage of the design process are suggested, and each of the genres then considered with respect to these design stages. Delineation along the lines of genre is not straightforward as attributes often overlap. However, Fig. 6 suggests how the games can be assigned to Pugh's design model, and the potential application of these is described below.

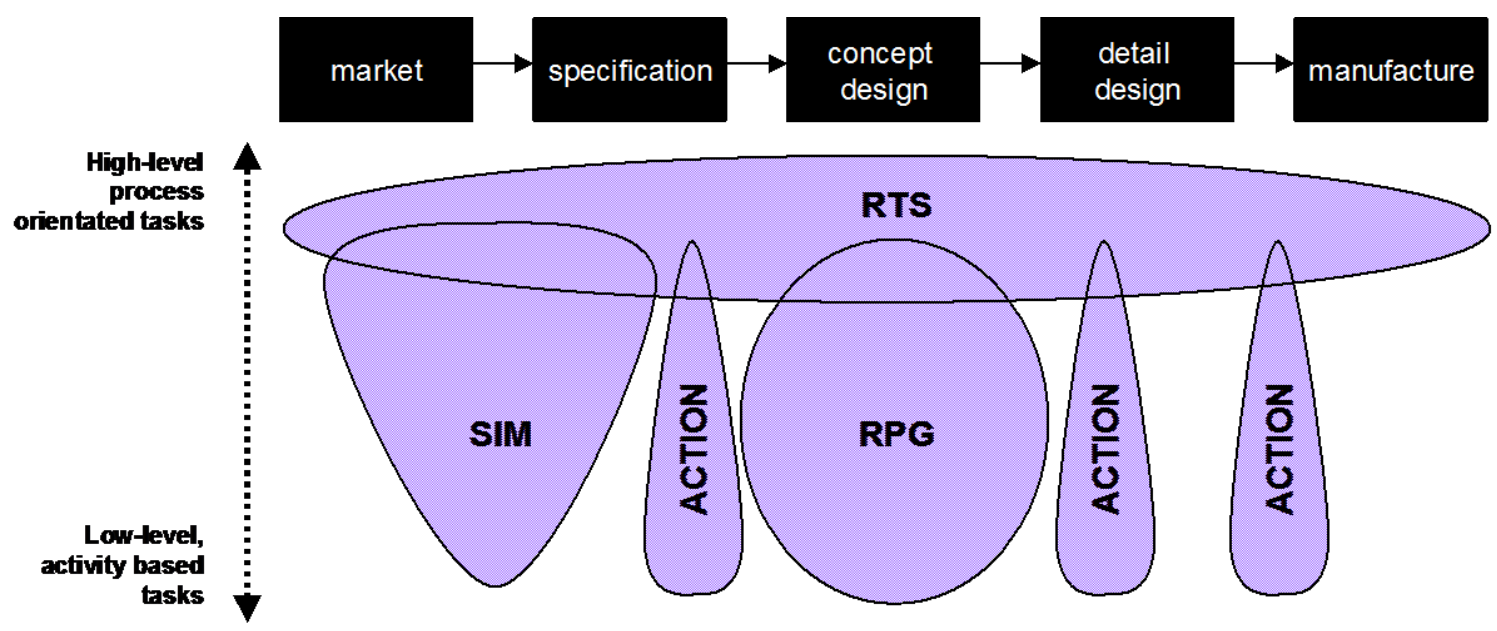

Figure 6: Genres in relation to the design process

RTS games provide a mixture of action and strategy based gameplay, involving a number of people in a shared, dynamic environment, and therefore have great potential to be adapted to the overall management of a design team. They generally involve the manipulation of avatars within situations of medium to high pressure demanding both micro- and macro-management strategies to successfully complete them. They can lack realism, but by making the interface most appropriate to content can provide an effective way of simulating systems in an exciting way. Other gaming modules, consisting of gameplay elements from other genres, could feed into this overall 'strategy environment' where the high-level management of the project is ongoing.

Sim games rely less on pressure and risk and more on the elements of engagement and interaction. This is because decisions are constantly being made as an intricate simulation builds, with the player becoming more and more involved in the world they are creating. This is not to say that the decisions made are not consequential. In fact, providing adequate information and having tangible consequences are crucial for a game's success but the number of decisions means that the player always has a chance to redeem past mistakes. Sim type games, therefore, provide a good foundation for learning about specific environments and systems by balancing a number of variables in a low-pressure format and are suited to familiarising designers with a new problem and identifying design constraints. One key problem lies in the huge amount of programming effort to create a game for each new environment. It may be possible to design a generic system which allows certain key information to be entered which is specific to the design problem, and this then allows players to experiment with variables and view possible outcomes. It is envisaged that these higher level management based activities would then be absorbed in the overall game strategy (the RTS environment). 
RPG games tend to consist of a high degree of contextualisation, with the player going through a fictitious situation which requires imagination, response and decision-making. This could be applied to the conceptual stages of design thinking, where divergent thought is encouraged. Analogy, stimulation and conversation can all be readily incorporated into gameplay similar to that of current games and these are recognised methods of stimulating new ideas in design. The ideas created in both the task orientated exercises and the managed direction of the concept work can be readily captured in the digital environment and returned to the overall game strategy (RTS) environment.

Action games rely very much on risk and pressure for gameplay success. Although this type of game can be exhilarating, the integration of useful content can be difficult as they are extremely context specific. However, this type of rapid task completion could be used to help revitalise traditional design task such as evaluating a concept 'against the clock', racing to complete a part design or competing to spot the most errors in an assembly. These would be primarily short, sharp synchronous exercises introduced at specific points in the design process with the inputs and outputs relating directly to the overall RTS environment.

\subsection{Adapting the design process}

Design teams are increasingly dispersed as part of knowledge clusters which contribute specific expertise to the design process, possibly on a range of projects as part of a matrix, or similar, design organisation (Lahti et al, 2004). Where such dispersion occurs there is a need to provide means of communication that support interaction and the precise transfer of ideas while minimising duplication of effort or overlap between individuals.

As well as its simplicity, Pugh's model was selected as the framework for the mapping of games to the design process because of its concern for cross-discipline visibility. This transparency is one of the key advantages of a shared virtual environment: it allows people to represent themselves (in the form of avatars or similar) so their location or activity can be monitored at a given time. This could be achieved by a shared interface based on the properties of the RTS genre which represents the design process as suggested by Fig. 7. Various tools are placed on the 'islands', and each of these tools could be adapted to form a 'game'. The designer can work around these islands by playing games at each stage to complete set tasks, allowing the design to develop. By having the game framework, the inputs and outputs can be controlled, providing a support structure which is particularly useful for novice designers in learning how to navigate through the process, but also for design teams in terms of co-ordinating people and effort.

The 'design core' is another key aspect of Pugh's design methodology, and this has the potential to be developed to utilise some of the benefits provided by a digital, interactive design environment. The design core is essentially the process of ensuring that the final design meets the PDS. This is generally achieved by running through a series of steps (concept design, detail design, manufacture etc.). Pugh does qualify this by adding that a degree of iteration should be employed through each stage, but in presentation and practise, the designer perceives progress as a linear path. Treating the design process in a more interactive way, however, lends itself to a gaming mindset of repeatedly trying something until the desired result is achieved. The low-risk environment of the Sim game makes adventurous but sound decision making more viable. Pugh's model has therefore been adapted, with the PDS now placed at the heart of the design process. This would require that for the designer to move from one stage to the other, the design criteria (PDS) 
must be re-evaluated against the current design. This could take a form similar to a Sim game environment, where constraints are constantly managed to achieve the optimum output.

The strategy board has been expanded in the area of concept design since Pugh's catchall of 'concept design' does not cover the varied important activities which take place in this part of the design process. It is here that RPG games have the potential to affect how information is handled and decisions made which will have most impact on design direction. Their structure is conducive to helping with divergent thinking by placing players in unfamiliar environments and encouraging them to do things in ways they usually would not but can also help with convergent aspects by asking questions which endorse a design's credibility. Other discrete games or activities would be required both in this and other islands and for particular synchronous design tasks action games may be able to provide an intense and exciting forum to complete activities such as concept evaluation, part design or error checking.

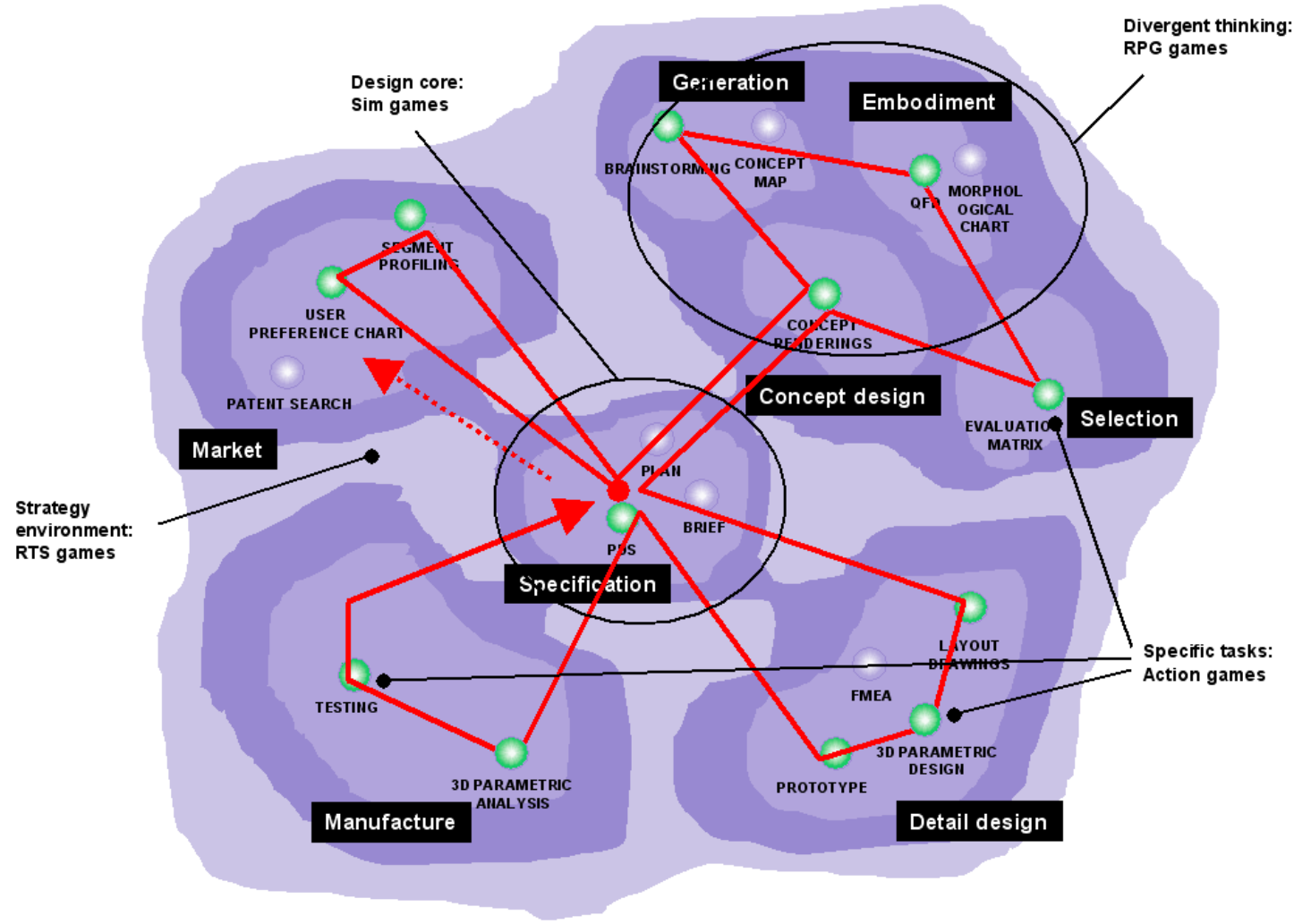

Figure 7: Revised product development process

\section{Conclusions}

This study sought to answer two main research questions, the first regarding how computer gaming techniques and strategies could be used to enhance communication and group design activites. It has been shown that various game genres have clear characteristics which can be applied to specific areas of the design process: RTS games have a mixture of action and strategy which lend themselves to organisational aspects of teams, and as a managment tool utilising the continuous and dynamic decision making environment; Sim games require a large number of 'micro-decisions' based on specific 
data with continuous feedback from a complex system, suggesting use in the early stages of design where information is acquired and decisions made on the direction of development; RPG games are immersive experiences where a player navigates a virtual world through structured interaction - ideal for problem-solving and creative situations where a group of people interact to develop new ideas; and action games are suited to specific simulation tasks which involve intense, synchronous activity to complete a design activity.

The second research question was how the most desirable features could be combined and utilised by designers. To this end, a novel structural representation of the design process which uses principles associated with the RTS genre to provide a game strategy environment has been suggested. This allows individual team members to work and interact as well as providing a general oversight of the design process. A design core which relies on the balancing of constraints in a manner to that of Sim games has been proposed. Rather than a stage of the design process, this is envisaged as a hub which is returned to constantly as the design process continues. The application of RPG game structures to concept design and action game formats to specific tasks have also been highlighted.

This study has focussed on the need for enhanced communications as part of engineering design, along with the possibility of using a strategy based on techniques developed in computer gaming for managing a design team and undertaking specific activities. Although the application of game genres and characteristics have been identified as applicable to certain parts of the design task, more work is required on how these can be integrated into a typical product development process. Some of these ideas can be implemented on a conceptual level: design teams can be reorganised and tasks arranged to be completed through the use of gameplay. To engage global design teams with a new collaborative environment, however, will require the development of new software aimed specifically at the design industry which will help consolidate and coordinate the tools already available. It is hoped that the insights provided by this study will assist in the identification of currently available game genres and features which can be applied.

\section{Acknowledgments}

This paper is partly based on a report which was written for BusinessLab as part of the Play2Win collaborative research programme on how a game-based approach to learning can help organisations motivate, train and develop employees to enhance their performance.

\section{References}

BusinessLab (2005) http://www.businesslab.co.uk/.

Play to Win (2005) http://www.iccave.com/Web/Site/ResearchApplications/Play2Win.asp.

Asakawa, T. and Gilbert, N. (2003) Synthesizing experiences: Lessons to be learned from Internet-mediated simulation games. Simulation \& Gaming, 34, 10-22.

Broadbent, J. A., Cross, N., Rodgers, P. A., Huxor, A. P. and Caldwell, N. H. M. (1999) Design Support Using Distributed Web-Based Al Tools. Research in Engineering Design, $11,31-44$. 
Coyne, R. (2003) Mindless repetition: Learning from computer games. Journal of Design Studies, 24, 199-212.

Davis, J. G. (2000) Creating Shared Information Spaces to Support Collaborative Design Work. Institute for Complex Engineered Systems, Carnegie Mellon University.

Fairbank, J. F., Spangler, W. E. and Williams, S. D. (2003) Motivating creativity through a computer-mediated employee suggestion management system. Behaviour \& Information Technology, 22, 305-314.

Gee, J. P. (2003) What Video Games Have to Teach Us About Learning and Literacy, Palgrave Macmillan.

Goldenberg, J. and Mazursky, D. (2002) Creativity in Product Innovation, Cambridge University Press.

Ip, B. and Jacobs, G. (2004) Quantifying game design. Design Studies, 25, 607-624.

Lahti, H., Seitamaa-Hakkarainen, P. and Hakkarainen, K. (2004) Collaboration patterns in computer supported collaborative designing. Design Studies, 25, 351-371.

Manninen, T. (2003) Interaction Forms and Communicative Actions in Multiplayer Games. Game Studies, 3.

Manninen, T. (2001) Rich Interaction in the Context of Networked Virtual EnvironmentsExperiences Gained from the Multi-player Games Domain. HCI 2001/ IHM 2001. SpringerVerlag. 383-398.

Mark, G. and Wulf, V. (1999) Changing interpersonal communication through groupware use. Behaviour \& Information Technology, 18, 385-395.

Newman, J. (2002) The Myth of the Ergodic Videogame: Some thoughts on playercharacter relationships in videogames. Game Studies, 2.

Norman, D. (2004) Emotional Design: why we love (or hate) everyday things, Basic Books.

Pahl, G. and Beitz, W. (1988) Engineering Design, A Systematic Approach, The Design Council.

Prensky, M. (2001) Digital Game-Based Learning, McGraw-Hill.

Pugh, S. (1991) Total Design, Addison-Wesley.

Rogers, P. and Lea, M. (2005) Social presence in distributed group environments: the role of social identity. Behaviour \& Information Technology, 24, 151- 158.

Roller, D., Eck, O. and Dalakakis, S. (2002) Advanced database approach for cooperative product design. Journal of Engineering Design, 13, 49-61.

Squire, K. (2002) Cultural Framing of Computer/Video Games. Game Studies, 2.

Ulrich, K. T. and Eppinger, S. D. (1995) Product Design and Development, McGraw-Hill. 
Wodehouse, A. and Bradley, D. (2003) Computer tools in product development. ICED 03. Stockholm. 333-334. 